\title{
DEVELOPMENT AND VALIDATION OF RAPID REVERSE PHASE HIGH-PERFORMANCE LIQUID CHROMATOGRAPHY METHOD FOR SIMULTANEOUS ESTIMATION OF STIGMASTEROL AND $\beta$-SITOSTEROL IN EXTRACTS OF VARIOUS PARTS (LEAVES, STEMS, AND ROOTS) OF XANTHIUM STRUMARIUM LINN.
}

\author{
POOJA ATRI, MANISHA BHATTI, ANJOO KAMBOJ*
}

Department of Pharmaceutical Chemistry Chandigarh College of Pharmacy, Landran, Mohali, Punjab, India. Email: anjookamboj@gmail.com Received: 02 September 2016, Revised and Accepted: 22 September 2016

\section{ABSTRACT}

Objective: Xanthium strumarium is a cocklebur or burweed belonging to family Asteraceae and commonly found as a weed, is widely distributed in North America, Brazil, China, Malasia, and hotter part of India. The herb is traditionally used mostly in treating several ailments. The present study deals with development and validation of a reliable reverse phase high-performance liquid chromatography (RP-HPLC) method for the simultaneous estimation of Stigmasterol and $\beta$-sitosterol in the various extracts of the plant.

Methods: The proposed method utilizes a Qualisil Gold C18 column $(250 \times 4.6 \mathrm{~mm}), 5 \mu \mathrm{m}$ particle size, under isocratic elution conditions with the mixture of acetonitrile:ethanol:water $(85: 14: 1 \mathrm{v} / \mathrm{v} / \mathrm{v})$ at $25^{\circ}$ as a mobile phase. An effluent flow rate of $1 \mathrm{ml} / \mathrm{minute}$ and ultraviolet detection at $202 \mathrm{~nm}$ was used for the analysis of Stigmasterol and $\beta$-sitosterol.

Results: The described method was linear in the range of range of $100-500 \mu \mathrm{g} / \mathrm{ml}$ and $10-500 \mu \mathrm{g} / \mathrm{ml}$ for stigmasterol and $\beta$-sitosterol respectively, with excellent correlation coefficients. The precision, robustness, and ruggedness values were also within the prescribed limits $(<2 \%)$. The recovery values were within the range, which indicates that the accuracy of the analysis was good and that the interference of the matrix with the recovery of phytosterols was low. The phytosterols were found to be stable in a stock solution for 24 hrs (percentage relative standard deviation was below $2 \%$ ) and no interfering extra peaks were observed under controlled stress conditions.

Conclusion: The proposed method is simple, specific, precise, accurate, and reproducible and thus can be used as appropriate method for routine analysis of $X$. strumarium phytosterols in quality control laboratories.

Keywords: Xanthium strumarium, Reverse phase high-performance liquid chromatography method, Precision, Phytosterols, Quality control.

(C) 2017 The Authors. Published by Innovare Academic Sciences Pvt Ltd. This is an open access article under the CC BY license (http://creativecommons. org/licenses/by/4. 0/) DOI: http://dx.doi.org/10.22159/ajpcr.2017.v10i1.15021

\section{INTRODUCTION}

Xanthium strumarium is a cocklebur or burweed belonging to family Asteraceae and commonly found as a weed in roadsides, rice fields, hedges throughout the tropical parts of India. It is commonly called chotagokhru due to the shape of its fruit which look likes the cow's toe. The whole plant is used as medicine. According to Ayurveda, the plant has cooling, laxative, fattening, anthelmintic, tonic, digestive, antipyretic activities and improves appetite, voice, complexion, and memory. It cures leukoderma, biliousness, and poisonous bites of insects, epilepsy, salivation, and fever. It is used by various Native American tribes to relieve constipation, diarrhea, and vomiting. Indigenous Chinese applications are as a headache remedy and to assist with cramping and numbness of the limbs, ulcers, and sinus problems. The plant is considered to be useful in treating long-standing cases of malaria and is used as an adulterant for Datura stramonium [1-5].

In continuation of the investigation of bioactive metabolites from $X$. strumarium, the present work deals with quantitative simultaneous estimation secondary metabolites stigmasterol and $\beta$-sitosterol from the petroleum ether extract of leaf, stem, and root part of the plant. Reverse phase high-performance liquid chromatography (HPLC) is now still a most popular tool for herbal analysis. Hence, an attempt has been made to develop HPLC method for estimation of two phytoconstituents (stigmasterol and $\beta$-sitosterol) simultaneously from various parts (leaves, Stems, and roots) of X. strumarium. The developed analytical method was validated in accordance with international conference on harmonization (ICH) guidelines [6-10].

\section{METHODS}

\section{Chemicals and reagents}

Stigmasterol and $\beta$-sitosterol were obtained from Sigma-Aldrich, Germany. Acetonitrile, water, and ethanol (HPLC grade) were purchased from Merck ltd., India. The other chemicals used were of analytical grade.

\section{Authentication of plant material}

Fresh and fully grown plants were collected near the roadways of a college campus in the month of October. The sample was authenticated by comparing the morphological characters as described in the literature. The authentication was further confirmed by Dr. H.B. Singh, Chief Scientist, and Head, Raw Materials Herbarium and Museum, NISCAIR, New Delhi. An herbarium sample of this plant is preserved in the Department, Chandigarh College of Pharmacy, Landran (Mohali) for future reference $\mathrm{CCP} / \mathrm{HB} / \mathrm{PA} / 01$.

\section{Collection and preparation of plant materials}

$X$. strumarium L. were collected in bulk quantity after confirmed authenticity from Landran, Mohali (Punjab) in the month of October. The plant parts such as leaves, stems, and roots were manually separated. The plant material was washed with water to remove soil, mud, debris, and other adhering materials and dried thoroughly in air under shade at room temperature. Coarse powder of each drug was prepared, passed through sieve \# 40 and stored in air tight container. 


\section{Extraction}

Extraction of sterols from the powder of leaves, stems, and roots was carried out using soxhlet extraction method using petroleum ether $\left(60^{\circ}-80^{\circ}\right)$ as a solvent. Then, the solvent is evaporated in rota evaporator at $60^{\circ} \mathrm{C}$ until semi-solid consistency. The extracts were dried to constant solid mass in a desiccator and were preserved in desiccator till further use.

\section{Optimization of chromatographic conditions}

The chromatographic conditions were optimized using different columns, flow rates, and mobile phase compositions given in Table 1,2. After optimization final solvent system selected was acetonitrile: ethanol:water (85:14:1 V/V/V) and flow rate were $1 \mathrm{ml} /$ minute as it gives a good resolution of the components.

A solution of $1 \mathrm{mg} / \mathrm{ml}$ and Shimadzu LC-2010cHT equipped with a spectrophotometric ultraviolet-visible (UV-VIS) detector were used Chromatographic separation was carried out using a column of qualisil gold C18, $250 \times 4.6 \mathrm{~mm}, 5 \mu \mathrm{m}$ particle size, under isocratic conditions with a mixture of acetonitrile:ethanol:water $(85: 14: 1 \mathrm{~V} / \mathrm{V} / \mathrm{V})$ as a mobile phase at the flow rate of $1 \mathrm{ml} /$ minute and injection volume was $20 \mu \mathrm{l}$. Then, using the areas under the peak, the percentage purity was calculated.

\section{Development and validation of HPLC method [6-10]}

\section{Preparation of the reference solution}

Stock solution of $1 \mathrm{mg} / \mathrm{ml}$ in methanol of standard stigmasterol and $\beta$-sitosterol were prepared. Further, different dilutions were prepared from stock solution. The samples were sonicated for 30 minutes, filtered through a membrane filter of $0.22 \mu \mathrm{m}$.

Shimadzu LC-2010CHT equipped with a spectrophotometric UV-VIS detector was used. Chromatographic separation was carried out using a column of Qualisil Gold C18, 250×4.6 mm, $5 \mu \mathrm{m}$ particle size, under isocratic conditions with a mixture of acetonitrile:ethanol:water $(85: 14: 1 \mathrm{~V} / \mathrm{V} / \mathrm{V})$ as a mobile phase at the flow rate of $1 \mathrm{ml} / \mathrm{minute}$ and injection volume was $20 \mu$ l. Detection was performed at $202 \mathrm{~nm}$ with 30 minutes runtime (Table 1 ).

\section{Validation of developed method}

\section{Linearity and precision}

Calibration curves for stigmasterol $(10-500 \mu \mathrm{g} / \mathrm{ml})$ and $\beta$-sitosterol $(100-500 \mu \mathrm{g} / \mathrm{ml})$ were obtained from standard solutions at different concentrations. The precision of the system and the precision of the method were determined as recommended by ICH guidelines. For determination of the precision of the system, Stigmasterol, and

Table 1: Method parameters of HPLC system

\begin{tabular}{ll}
\hline Column & Qualisil gold C18, 250×4.6 mm, \\
& $\mathbf{5} \boldsymbol{\mu m}$ particle size \\
\hline Flow rate & $1 \mathrm{ml} /$ minute \\
Mobile phase & Acetonitrile: ethanol: water (85:14:1) \\
Run time & 30 minutes \\
Wavelength & $202 \mathrm{~nm}$ \\
Temperature of column & $40^{\circ} \mathrm{C}$ \\
Injection volume & $20 \boldsymbol{\mu l}$ \\
Sample solvent & Methanol \\
\hline
\end{tabular}

HPLC: Reverse phase high-performance liquid chromatography $\beta$-sitosterol were injected in six replicates on the same day. The acceptance criterion was $\pm 2 \%$ for the percentage relative standard deviation (RSD) of the peak area and retention time (RT). For the precision of the method, samples were prepared 6 times, and each of these was injected in duplicate. The precision was determined from the percentage RSD [6-10]

\section{Stability study}

The stability of phytosterols in standard stock solutions was investigated at different time intervals at room temperature. The experiment was also carried out to demonstrate the specificity of the developed method for the determination of stigmasterol and $\beta$-sitosterol under controlled conditions. The sample of specific concentration was drawn at 3,6 , 9 , and $24 \mathrm{hrs}$, and the peak area responses were recorded under the optimized chromatographic condition.

\section{Robustness and ruggedness}

The robustness and ruggedness of the method were investigated by varying the chromatographic conditions, such as the flow rate $( \pm 10 \%)$, the wavelength of detection $( \pm 10 \mathrm{~nm})$ and varying the analysts. The results were indicated by the percentage RSD between the data at each variable condition.

\section{Limit of detection (LOD) and limit of quantification (LOQ)}

LOD and LOQ were determined based on solutions of the standard used to construct the calibration curve. LOD and LOQ were calculated using the formula based on standard deviation of response and the slope of the calibration curve. LOD and LOQ were calculated using equations:

$\mathrm{LOD}=3.3 \frac{\sigma}{\mathrm{s}}$

$\mathrm{LOQ}=10 \frac{\sigma}{\mathrm{s}}$

Where $S$ is the slope of the calibration curve and $\sigma$ is the standard deviation of regression equation intercept $(n=10)$.

Estimation of phytosterols content from petroleum ether extracts of leaves, stems, and roots

The optimized HPLC method was used to estimate the phytosterols in petroleum ether extracts of leaves, stems, and roots of X. strumarium. The solutions of each extract were prepared separately by dissolving $(10 \mathrm{mg} / \mathrm{ml})$ in chloroform, and a sample of $20 \mu \mathrm{l}$ was subjected to HPLC analysis, and the peak area responses were recorded under the optimized chromatographic condition. From the linear regression equation percentage content was determined. The identification of stigmasterol and $\beta$-sitosterol in extracts was preferred by comparison of RT. The samples of a standard solution of extracts were stored in the dark to avoid oxidative degradation.

\section{RESULTS AND DISCUSSION}

\section{Optimization of chromatographic conditions}

A method based on reversed phase HPLC separation combined with UV-VIS detection has been developed for phytosterols analysis in $\mathrm{X}$. strumarium. An isocratic elution was chosen since it is simple, requires only one pump and minimizes the variation of baseline and ghost peaks. For RP-HPLC, various columns are available, but a column: Qualisil Gold C18, 250×4.6 mm, $5 \mu \mathrm{m}$ Particle size was preferred because its peak shape and resolution were better. During optimization of method conditions, among the different mobile phases employed,

Table 2: Optimization of chromatographic conditions

\begin{tabular}{llllll}
\hline Solvent systems & Mode & Mobile phase composition & Column & Flow rate & RT (minute) $\boldsymbol{\beta}$-sitosterol \\
\hline ACN: ethanol & Isocratic & $85: 15$ & C $8,250 \times 4.6 \mathrm{~mm}$ & 2 \\
ACN: water: ethanol & Isocratic & $85: 5: 10$ & $\mathrm{C} 18,250 \times 4.6 \mathrm{~mm}$ & 1 & 25.6 \\
ACN: water: ethanol* & Isocratic* & $85: 1: 14^{*}$ & $\mathrm{C} 18,250 \times 4.6 \mathrm{~mm}^{*}$ & $1^{*}$ & 2.8 \\
ACN: water: ethanol & Isocratic & $90: 1: 09$ & $\mathrm{C} 18,250 \times 4.6 \mathrm{~mm}$ & 1 & $8.3^{*}$ \\
\hline
\end{tabular}

*Most optimized chromatography condition, RT: Retention time 
mobile phase: acetonitrile:ethanol:water $(85: 14: 1)$ was found to be suitable for analysis of stigmasterol and $\beta$-sitosterol. Further, a flow rate of $1 \mathrm{ml} /$ minute and an injection volume of $20 \mu \mathrm{l}$ along with UV detection at $202 \mathrm{~nm}$ were found to be optimal conditions for analysis of these phytosterols (Figs. 1-4 and Tables 1 and 2).

HPLC chromatogram of standard stigmasterol and $\beta$-sitosterol obtained under optimized chromatographic conditions by injecting $20 \mu \mathrm{l}$ of $10 \mu \mathrm{g} / \mathrm{ml}$ solution. RT for stigmasterol and $\beta$-sitosterol was found to be 7.77 and 8.49 , respectively which were in good agreement with reported data.

\section{HPLC method development and validation}

Linearity

Calibration curve for stigmasterol and $\beta$-sitosterol were obtained from standard solutions at different concentrations. The linearity of the HPLC method was investigated over range $100-500 \mu \mathrm{g} / \mathrm{ml}$ and $10-500 \mu \mathrm{g} / \mathrm{ml}$ for stigmasterol and $\beta$-sitosterol, respectively. The calibration curve for stigmasterol and sitosterol were found to linear, with excellent correlation coefficients $\left(\mathrm{R}^{2}=0.9958\right.$ and 0.990 , respectively). The typical calibration curves of stigmasterol and $\beta$-sitosterol have the regression equation, $Y=1266.86 \mathrm{X}+299118$, and $\mathrm{Y}=1056 \mathrm{X}+383241$, respectively (Figs. 3 and 4).

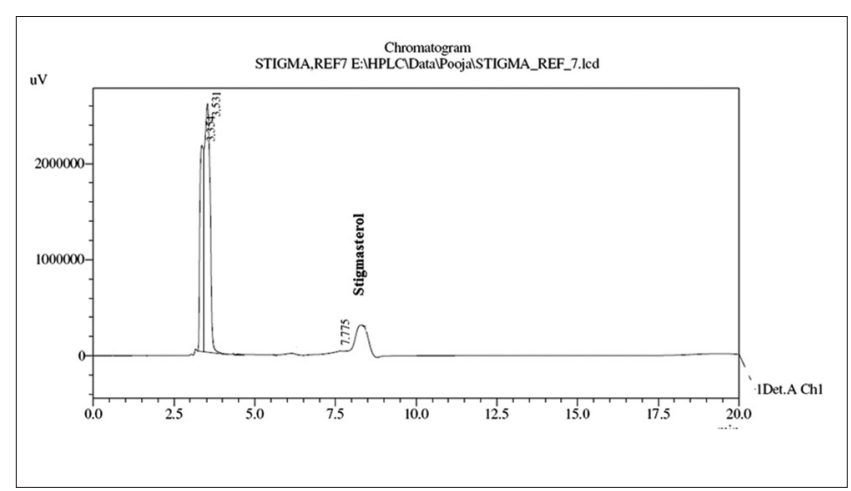

Fig. 1: Reverse phase high-performance liquid chromatography chromatogram of standard stigmasterol at $202 \mathrm{~nm}$

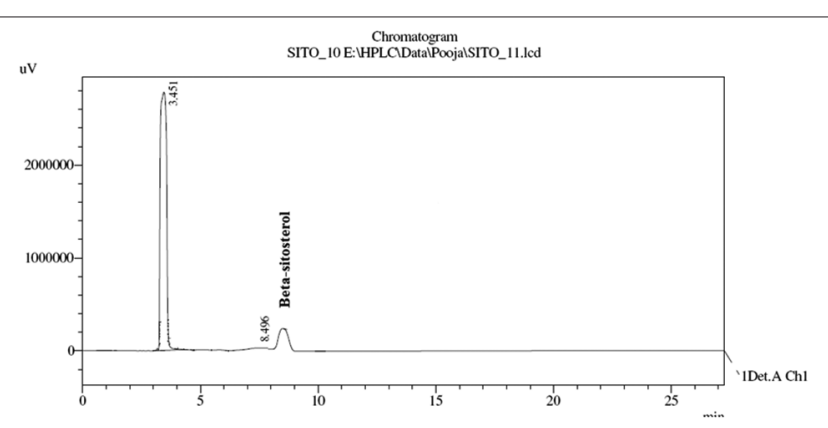

Fig. 2: Reverse phase high-performance liquid chromatography chromatogram of standard $\beta$-sitosterol at $202 \mathrm{~nm}$
System and method precision

The system precision results indicate that the pecentage RSD values were 1.33 and 0.027 (RT and peak area, respectively) for stigmasterol and 1.2 and 0.024 (RT and peak area, respectively) for $\beta$-sitosterol, which are well within the prescribed limits of the ICH guidelines (percentage RSD $<2 \%$ ). Similarly, the results obtained for the precision of the method are within the prescribed limit (percentage RSD $<2 \%$ ), with the percentage RSD values of the peak area being 0.38 and 0.053 for stigmasterol and $\beta$-sitosterol, respectively (Table 3).

\section{Stock solution stability}

Stability of stock solution was determined for the different time interval. Then the SD and RSD were calculated to check its accuracy. The phytosterols were found to be stable in stock solutions for $24 \mathrm{hrs}$ The percentage RSD values were 0.061 and 0.021 for stigmasterol and $\beta$-sitosterol, respectively (Table 4).

\section{Robustness and ruggedness}

The robustness and ruggedness of the method were investigated by varying the chromatographic conditions, such as the flow rate $\pm \pm 10 \%)$, wavelength of detection $( \pm 5 \mathrm{~nm})$, and varying the analysts. The results were indicated by the percentage RSD between the data at each variable condition (Table 5).

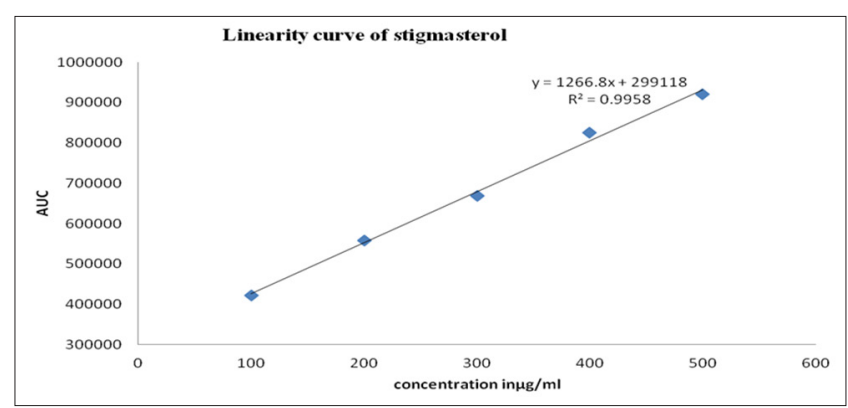

Fig. 3: Calibration curve of stigmasterol $(100-500 \mu \mathrm{g} / \mathrm{ml})$ by reverse phase high-performance liquid chromatography method. Values are expressed as mean of six determinants

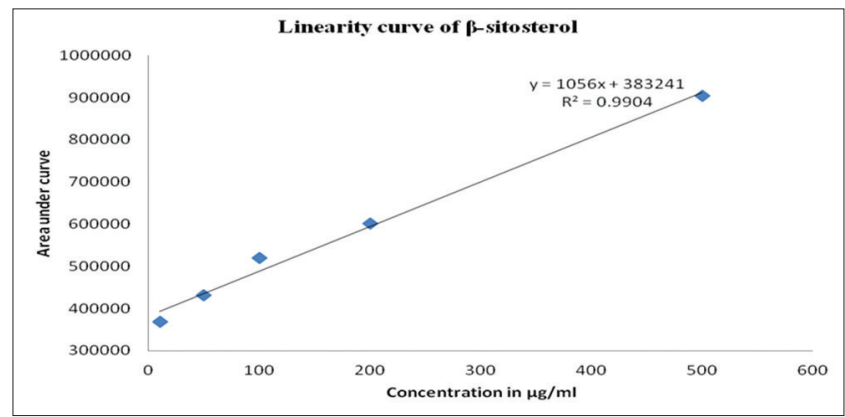

Fig. 4: Calibration curve of $\beta$-sitosterol $(10-500 \mu \mathrm{g} / \mathrm{ml})$ by reverse phase high-performance liquid chromatography method. Values are expressed as mean of six determinants

Table 3: System and method precision data

\begin{tabular}{|c|c|c|c|c|c|c|}
\hline \multirow[t]{3}{*}{ Parameter } & \multicolumn{4}{|c|}{ System precision } & \multicolumn{2}{|l|}{ Method precision } \\
\hline & \multicolumn{2}{|c|}{$\begin{array}{l}\text { Stigmasterol } \\
\text { (concentration } 100 \mu \mathrm{g} / \mathrm{ml} \text { ) }\end{array}$} & \multicolumn{2}{|c|}{$\begin{array}{l}\beta \text {-sitosterol } \\
\text { (concentration } 10 \mu \mathrm{g} / \mathrm{ml} \text { ) }\end{array}$} & \multirow{2}{*}{$\begin{array}{l}\text { Stigmasterol } \\
\text { (concentration } 100 \mu \mathrm{g} / \mathrm{ml} \text { ) }\end{array}$} & \multirow{2}{*}{$\begin{array}{l}\beta \text {-sitosterol } \\
(\text { concentration } 10 \mu \mathrm{g} / \mathrm{ml} \text { ) }\end{array}$} \\
\hline & RT & Peak area & RT & Peak area & & \\
\hline Mean \pm SD & $7.803 \pm 0.12$ & $421808 \pm 115.4$ & $8.917 \pm 0.109$ & $368819 \pm 89.48$ & $422780 \pm 121.4$ & $378872 \pm 98.1$ \\
\hline \%RSD & 1.33 & 0.027 & 1.2 & 0.024 & 0.38 & 0.053 \\
\hline
\end{tabular}

Values are expressed as mean of six determinants, RSD: Relative standard deviation, RT: retention time 
The RP-HPLC method is robust and rugged since the percentage RSD values are lower than $2 \%$ for all four variables.

\section{LOD and LOQ}

The results further reveal that the minimum concentration levels at which the analyte can be reliably LOD and LOQ are $3.46 \mathrm{ng} / \mathrm{ml}$ and $10.5 \mathrm{ng} / \mathrm{ml}$ for stigmasterol and $10.5 \mathrm{ng} / \mathrm{ml}$ and $12.2 \mathrm{ng} / \mathrm{ml}$ for $\beta$-sitosterol, respectively, demonstrating the sensitivity of the method (Table 6).

Table 4: Stock solution stability data

\begin{tabular}{lll}
\hline Time (h) & $\begin{array}{l}\text { Stigmasterol } \\
\text { (concentration } \\
\mathbf{1 0 0} \boldsymbol{\mu g} / \mathbf{m l} \text { ) }\end{array}$ & $\begin{array}{l}\boldsymbol{\beta} \text {-sitosterol } \\
\text { (concentration } \\
\mathbf{1 0} \boldsymbol{\mu g} / \mathbf{m l} \text { ) }\end{array}$ \\
\hline 3 & 558493 & 431693 \\
6 & 558518 & 431598 \\
9 & 557898 & 431706 \\
24 & 558469 & 431623 \\
Mean \pm SD & $558344.5 \pm 341.4$ & $431655 \pm 91.94$ \\
Percentage RSD & 0.061 & 0.021 \\
\hline
\end{tabular}

Values are expressed as mean of three determinants, RSD: Relative standard deviation, SD: Standard deviation

Table 5: Robustness and ruggedness data

\begin{tabular}{lll}
\hline Parameter & \multicolumn{2}{l}{ percentage RSD of peak area } \\
\cline { 2 - 3 } & Stigmasterol & $\boldsymbol{\beta}$-sitosterol \\
\hline Flow (2 ml/minute) & 0.65 & 0.39 \\
Flow (0.5 ml/minute) & 0.63 & 0.37 \\
Wavelength (198) & 0.82 & 0.93 \\
Wavelength (202) & 0.88 & 1.23 \\
Analyst-I & 0.48 & 0.54 \\
Analyst-II & 0.46 & 0.54 \\
\hline
\end{tabular}

Values are expressed as mean of three determinants, RSD: Relative standard deviation

Table 6: Method validation parameters for the quantization of stigmasterol and $\beta$-sitosterol by HPLC method

\begin{tabular}{|c|c|c|}
\hline Parameters & Stigmasterol & $\beta$-sitosterol \\
\hline Linear range & $100-500 \mu \mathrm{g} / \mathrm{ml}$ & $10-500 \mu \mathrm{g} / \mathrm{ml}$ \\
\hline $\begin{array}{l}\text { Correlation } \\
\text { coefficient }\end{array}$ & 0.995 & 0.990 \\
\hline $\begin{array}{l}\text { Linear regression } \\
\text { equation }\end{array}$ & $Y=1266.8 X+299118$ & $Y=1056 X+383241$ \\
\hline LOD & $3.46 \mathrm{ng} / \mathrm{ml}$ & $3.99 \mathrm{ng} / \mathrm{ml}$ \\
\hline LOQ & $10.5 \mathrm{ng} / \mathrm{ml}$ & $12.2 \mathrm{ng} / \mathrm{ml}$ \\
\hline $\begin{array}{l}\text { Repeatability } \\
(\% \text { RSD, } n=6)\end{array}$ & 1.33 & 1.28 \\
\hline $\begin{array}{l}\text { System } \\
\text { precision (\%RSD) }\end{array}$ & 0.027 & 0.024 \\
\hline $\begin{array}{l}\text { Method } \\
\text { precision (\%RSD) }\end{array}$ & 0.38 & 0.053 \\
\hline Stability & $24 \mathrm{hrs}$ & $24 \mathrm{hrs}$ \\
\hline
\end{tabular}

HPLC: Reverse phase high-performance liquid chromatography, RSD: Relative standard deviation, LOD: Limit of detection, LOQ: Limit of quantification
Quantification of phytosterols in petroleum ether extracts of leaves, stems, and roots of $X$. strumarium

To apply the developed and validated RP-HPLC method, the two solutions of each were analyzed to identify and quantify the stigmasterol and $\beta$-sitosterol in the extracts. HPLC chromatogram for the petroleum ether extract of leaves, stems, and roots of $X$. strumarium were recorded, and peak area was determined in triplicate using calibration curve or

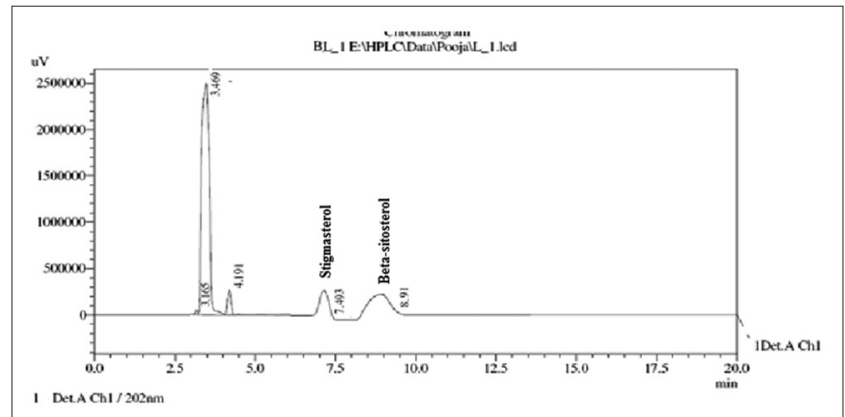

Fig. 5: Reverse phase high-performance liquid chromatography chromatogram of petroleum ether extract of leaves of Xanthium strumarium at $202 \mathrm{~nm}$

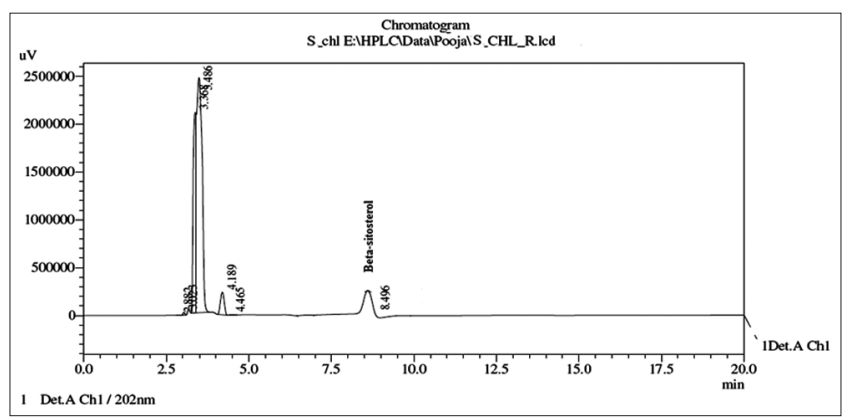

Fig. 6: Reverse phase high-performance liquid chromatography chromatogram of petroleum ether extract of stems of Xanthium strumarium at $202 \mathrm{~nm}$

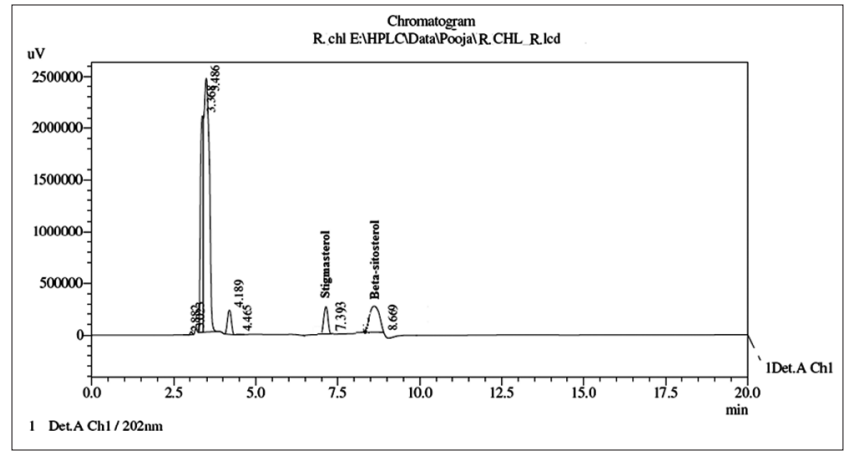

Fig. 7: Reverse phase high-performance liquid chromatography chromatogram of petroleum ether extract of roots of Xanthium strumarium at $202 \mathrm{~nm}$

Table 7: Estimation of stigmasterol and $\beta$-sitosterol in leaves, stems, and roots of $X$. strumarium

\begin{tabular}{lllll}
\hline Petroleum ether extracts & \multicolumn{2}{l}{ Stigmasterol } & & \multicolumn{1}{l}{$\boldsymbol{\beta}$-sitosterol } \\
\cline { 2 - 3 } & Peak area mean \pm SD & Content percentage & & Peak area mean \pm SD \\
\hline Leaves & $506362 \pm 0.031$ & 1.63 & $388361 \pm 0.019$ \\
Stems & 0000 & 0.000 & 0.04 & 0.41 \\
Roots & $449816 \pm 0.021$ & 1.19 & $427325 \pm 0.32$ & 0.38 \\
\hline
\end{tabular}

Values are expressed as mean of three determinants, SD: Standard deviation, $X$. strumarium: Xanthium strumarium 
linear regression equation and percentage content were determined Percentage content of Stigmasterol and $\beta$-sitosterol were found to be $1.63 \%$ and $0.04 \% \mathrm{w} / \mathrm{w}$ respectively in petroleum ether extracts of leaves, $1.19 \%$ and $0.38 \% \mathrm{w} / \mathrm{w}$ respectively in roots and percentage content of $\beta$-sitosterol was found to be $0.41 \% \mathrm{w} / \mathrm{w}$ in petroleum ether extracts of stems of $X$. strumarium (Figs. 5-7, Table 7)

\section{CONCLUSION}

A simple, specific, precise, rapid, and reproducible HPLC method has been developed to quantify phytosterols, relevant marker compounds in petroleum ether extracts of leaves, stems, and root part of the $X$. strumarium. The method showed good linear relationship between the peak area and concentrations, acceptable reproducibility and high accuracy. Stigmasterol content was found to be higher in leaves and roots which were $1.63 \%$ and $1.19 \% \mathrm{w} / \mathrm{w}$ respectively than stem and $\beta$-sitosterol which was $0.04 \%, 0.41 \%$, and $0.38 \% \mathrm{w} / \mathrm{w}$ respectively in leaves, stems, and roots of $X$. strumarium. The validation procedure confirms that this is an appropriate method for quality control of extracts of $X$. strumarium. Finally, it was concluded that the method is simple, sensitive, and can separate the components from other in plant extracts and estimate them simultaneously.

\section{REFERENCES}

1. Rastogi RP, Mehrotra BN. Compendium of Indian medical plant. CDRI Lucknow NSIC New Delhi 1980-1984;3:685-6.

2. Kim Y, Won PJ, Jung H, Jung HJ, Park HJ, Choi JW, et al. Methanol extract of Xanthium strumarium L. possesses anti-inflammatory and anti-nociceptive activities. Biol Pharm Bull 2005;28(1):94-100.

3. Kamboj A, Saluja AK. Phytopharmacological review of Xanthium strumarium L. (Cocklebur). Int J Green Pharm 2010;4(3):129-39.

4. Kaur M, Kamboj A, Saluja AK. Isolation and characterization of constituents from the leaves of Xanthium strumarium and their evaluation for antioxidant and antimicrobial potential. Nat Prod Chem Res 2015;3:168.

5. Kamboj A, Atri P, Saluja AK. Phytochemical screening, in-vitro evaluation of antioxidant and free radical scavenging activity of leaves, stems and roots of Xanthium strumarium L., (Compositae). Br J Pharm Res 2014;4(1):1-22.

6. Shah UM, Patel SM, Patel PH, Hingorani L, Jadhav RB. Developmen and validation of a simple isocratic HPLC method for simultaneous estimation of phytosterols in Cissus quadrangularis. Indian J Pharm Sci 2010;72(6):753-8.

7. Subramanian G, Meyyanathan NS, Karthik Y, Karunakaranair A Palanisamy DS. Development and validation of HPLC method for the simultaneous estimation of quercetin and rutin in Aganosma dichotoma [Roth] K. Schum. Int J Pharm Pharm Sci 2014;6(2):606-8.

8. Maji AK, Pandit S, Banerji P, Banerjee D. A validated RP-HPLC method for simultaneous determination of betulin, lupeol, and stigmasterol in Asteracantha longifolia Nees. Int J Pharm Pharm Sci 2014;6(5):691-5

9. ICH. 2013. Available from: http://www.ich.org/products/guidelines/ quality/article/quality-guidelines.html.

10. Jain N, Jain R, Banweer J, Jain DK. Development and validation of a rapid RP-HPLC method for the determination of Amlodipine besylate and Olmesartan medoxomil in their combined tablet formulation. Int $\mathrm{J}$ Curr Pharm Res 2010;2(2):40-3 